\title{
Analysis of Mission Task Loading Based on the External Disturbance
}

\author{
Eunghyun Lee1, Suhwan Kim², Yongjin (James) Kwon ${ }^{*}$ \\ ${ }^{1}$ Departmant of Industrial Engineering, Ajou University, Suwon, South Korea \\ ${ }^{2} 1^{\text {st }}$ Division, $3^{\text {rd }}$ Department, Agency for Defense Development, Daejeon, South Korea \\ Email: ${ }^{*} y k 73 @ a j o u . a c . k r$
}

Received October 2015

\begin{abstract}
This research investigates the impact of changing weather conditions on the crew members who sit in a side-by-side cockpit, which is unusual for attack helicopters. Extensive review conducted by the authors fails to locate similar studies; hence a helicopter simulator is developed in order to conduct the experiments. The simulator represents the realistic flight characteristics as well as the digital cockpit instruments that contain the advanced mission equipment. During the experiments, a camcorder is used to record the pilots to accurately analyze the task completion time and the physical motions of both pilots. NASA-TLX is also used to collect the workload data to assess the impact of task assignments among the pilots. The analytical findings from this study will be instrumental in improving the cockpit design for enhanced mission effectiveness.
\end{abstract}

\section{Keywords}

Attack Helicopter, Task Assignment, Weather-Related Pilot Workload, TLX, Side-by-Side Cockpit

\section{Introduction}

Modern day attack helicopter is an indispensable asset in military operation. Several wars conducted over the last decades vindicate the lethal effects of this weapons platform. Equipped with high-tech surveillance, targeting, navigation, defense and offense systems, an attack helicopter acts as an eye-in-the-sky, ready to deliver a precision ordnance to enemy positions. The unique abilities, such as hovering, masking under the ground features, high speed cruise at low altitude, and flying under the radar (NOE: nap-of-the-earth flight), represent the flexibility, resilience, and lethality in the battlefield [1] [2]. It is highly cost effective as well, capable of destroying an enemy asset that is worth 17 times higher than its own production cost, before its own destruction [3]. Most attack helicopters prefer the tandem cockpit configuration because it allows a narrow frontal area to minimize the enemy detection and faster cruising speed. Also, it has completely separated pilot and gunner spaces for enhanced combat survivability. On the other hand, the side-by-side cockpit configuration is usually used for civilian helicopters. The side-by-side seating provides a wide field of view to both pilots for an unobstructed visibility. Since there is no physical barrier between the pilots, the crew communication is not as hin-

${ }^{*}$ Corresponding author. 
dered. This leads to the improved situational awareness, better coordination, and increased mission effectiveness. From the utility point of view, the space behind the cockpit area can be used to transport additional troops or carry other mission equipment, hence providing more flexibility. The major drawback to the side-by-side cockpit includes the difficulties associated with the installation of heavy, thick, large bullet-proof windscreen, which oftentimes exceed the acceptable weight increase. The speed reduction due to enlarged frontal sections, however, seems to be not extensive. Prior to this study, our preliminary study determined the mission profile as well as the work assignment between the pilot and gunner, who sits in a side-by-side cockpit. The various tasks required for the attack mission have been experimentally evaluated and optimally allocated for even workload. Under the situation, the aim of this study is to find out that, to what extent, the pilot and gunner are affected by the external environmental factors, including daytime, nighttime, bad weather and solo flights, Military flight operations are increasingly performed under adverse weather conditions [4]-[7].

\section{Experimental Procedure}

The side-by-side helicopter enables the pilot, who normally sits in the right, and the gunner, who occupies the left seat, to share the same working area and the flight instruments, thus allowing them to coordinate their tasks as situations demand. In theory, a pilot can perform the complete task without the aid from a gunner. However, the increased workload burdens the pilot, and distracts the pilot from performing other critical tasks, such as operating a defensive system and staying vigilant for possible threats. Especially, the target identification and enemy engagement require a full concentration. Therefore, in normal conditions, the pilot and gunner are assigned with separate tasks. This in turn enhances the chance of mission success and survival of the crew members [8]-[10]. The optimal task assignment developed through the experiments is shown in Table $\mathbf{1}$ and has been used for this research.

Figure 1 shows the outline of the attack helicopter simulator that has been developed for this study. Its flight characteristics are very similar to a real helicopter. The helicopter is controlled from the cockpit through the pilot input to the collective, cyclic, and rudder controls, which are arranged with oil dampers and pretension springs for realistic control feedback. The entire mission can be planned and controlled from the mission control station, while engagements can be simulated using the enemy stations. Up to three enemy assets, such as tank, anti-aircraft guns, vehicles, can be selected. Using the joy stick, they can engage the attack helicopter as in a real combat situation.

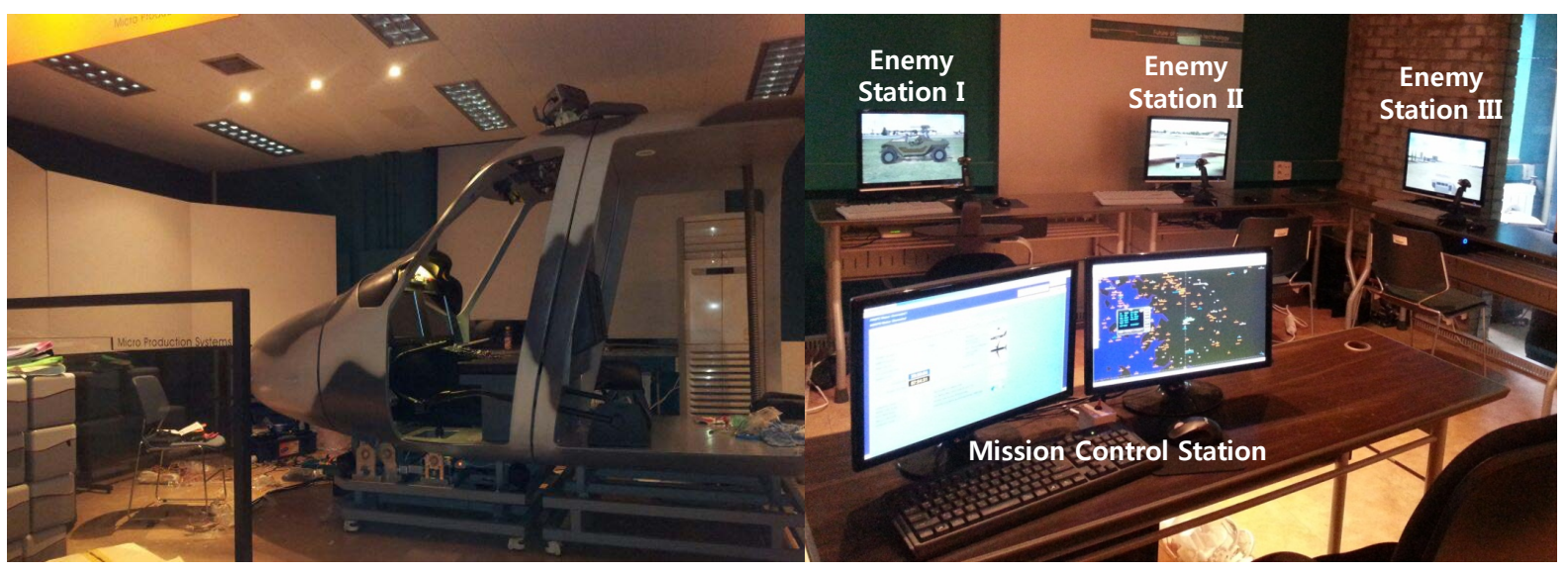

Figure 1. Experiment scenario and attack helicopter simulator.

Table 1. Pilot and gunner task assignment.

\begin{tabular}{lll}
\hline \multicolumn{1}{c}{ Pilot } & \multicolumn{1}{c}{ Gunner } & \multicolumn{1}{c}{ Common } \\
\hline -Departure \& return flight & -Operate guided missiles & -Evasion flight \\
-NOE (nap of the earth flight) & -Operate guided and unguided rockets & -Operation of chaff and flare \\
-Hovering, masking, unmasking & -Operate a $20 \mathrm{~mm}$ gun & -Scan of the surroundings for possible enemy threats \\
-Operate unguided rockets and a $20 \mathrm{~mm}$ gun & -Target sight control & -Radio communications \\
\hline
\end{tabular}


The flight instruments can be configured to display any information that the pilots need. The targeting sight (TS) is enabled with a night-time capability, built with zoom-in and out features for target identification. Weapons control allows the pilot to choose precision anti-armor missiles, guided and unguided rockets, and a $20 \mathrm{~mm}$ gun. When enemy radar tracks the helicopter, the caution and alarm signs are set off with the direction to the enemy radar displayed. We applied randomization and conducted 5 repetitions for each weather condition, thus performing a total of 20 flights. The data of the workload of the pilot was gathered by surveying with NASATLX, and the total amount of time spent for each task according to the work breakdown was recorded with a camcorder. The video clips from the camcorder were also subdivided with the interval of 5 seconds. The types of experiments are shown in Table 2. The superimposed inlet image on the right side of nighttime cockpit view illustrates a night vision mode of the targeting sight. Since wearing the night vision goggles were not feasible for our experiments, both pilots were relying on the targeting sight in nighttime flights. The scenario consists of the randomized location of the enemy encampment, which is accompanied by 4 targets (3 buildings and 1 tank). The helicopter that took off at the assigned starting point enters the operational area by contour flying and switches to NOE flight. It then goes to the location of reconnaissance. The pilot has to fly near to the target area, and the gunner must look for the target and identify the type through the TS. Once the target is confirmed, the helicopter moves to the first attack position with NOE flight, pops up (unmasking), and launches the missiles. Considering the fact that it has to be exposed to fire the weapon, the helicopter operates survival gears and does the evasion flight while transits to the next attack position. It attacks the assigned targets using the rockets, followed by a gun. Guided rockets rely on the laser beam projected on the enemy target. To engage the enemy targets with unguided rockets, the pilot must hover the helicopter precisely. The gun was operated with the TS for aiming. After neutralizing the four targets, it retreats from the operational area with NOE flight. The helicopter switches back to contour flying and lands on the forward base to end the scenario (see Figure 2). The flying time varies in accordance with the weather settings, which is in the range of 30 - 50 minutes.

\section{Time Data Analysis}

Setting the confidence level at 95\% and using the ANOVA, we applied the principle of time and motion study as to the recorded video clips. The mission is categorized into eight major tasks, according to the time and motion. Then, if possible, each major task is further divided into segments that indicate the important activities. Overall, the pilot has a total of 20 segments identified, while the gunner has 16 segments. Among the task breakdown, we identified a total of ten segments that are very difficult to differentiate between the experiments in terms of significance. Those segments are the routines that are performed consistently for all experiments. The code numbers include P_A1, P_B2, P_D1, P_E3, P_F3, P_G3, G_A1, G_D1, G_E4, and G_G2. The average completion time for each task and segment is represented in Table 3 and Table 4.

Any significant difference among the experiment settings is identified, and the p-values are illustrated. For the pilot, the Pop-up and Hovering show two different patterns. When the gunner operates guided weapons, the pilot time shows no significant variations among the experiments. However, when the gunner operates non-guided rockets, the pilot time fluctuates widely and becomes significant. This is due to the fact that the hit accuracy of non-guided weapons is dependent on the stable hovering. It requires a heavy concentration from the pilot to steadily maintain the attitude of the helicopter. For the pilot, the NOE flight time appears not significant for C1

Table 2. Result of time analysis (Pilot).

\begin{tabular}{|c|c|c|}
\hline Setting & Characteristic & Cockpit View \\
\hline Day & $\begin{array}{l}\text {-Operation starts at 12:00 hr/All clear weather } \\
\text {-Flight speed limit } 130 \mathrm{kts} / \text { Visibility unrestricted }\end{array}$ & \\
\hline Night & $\begin{array}{l}\text {-Operation starts at 24:00 hr/All clear weather } \\
\text {-Flight speed limit } 100 \mathrm{kts} / \text { Use of night vision }\end{array}$ & 1 \\
\hline $\begin{array}{c}\text { Bad } \\
\text { Weather }\end{array}$ & $\begin{array}{l}\text {-Operation starts at 12:00 hr/Light to medium rains with scattered fog } \\
\text {-Visibility less than } 2 \text { - } 3 \text { miles/Flight speed limit } 100 \mathrm{kts}\end{array}$ & \\
\hline Solo Flight & Same as the day experiment & \\
\hline
\end{tabular}


Table 3. Statistical analysis of the time data for the pilot.

\begin{tabular}{|c|c|c|c|c|c|c|c|c|}
\hline Task & Pilot & $\begin{array}{l}\text { Mission } \\
\text { Code }\end{array}$ & Daytime & $\begin{array}{c}\text { Bad } \\
\text { Weather }\end{array}$ & Nighttime & $\begin{array}{l}\text { Solo } \\
\text { Flight } \\
\end{array}$ & P-value & Significance \\
\hline \multirow{3}{*}{$\begin{array}{l}\text { Flight to } \\
\text { operation area }\end{array}$} & Check aircraft condition & P_A1 & 30 & 30 & 30 & 30 & N/A & N/A \\
\hline & $\begin{array}{c}\text { Take-off/Contour Flight } \\
\text { Radio communication } \\
\text { with command post }\end{array}$ & P_A2 & 58 & 67 & 77 & 55 & 0.00 & Yes \\
\hline & NOE Flight & P_A3 & 107 & 125 & 134 & 105 & 0 & Yes \\
\hline \multirow{3}{*}{$\begin{array}{l}\text { Capture } \\
\text { reconnaissance } \\
\text { point target } \\
\text { acquisition }\end{array}$} & $\begin{array}{l}\text { Radio communication } \\
\text { with command post }\end{array}$ & & 27 & $6 ?$ & 51 & 23 & ר & Y \\
\hline & $\begin{array}{l}\text { Pop-Up \& Hovering, } \\
\text { Target acquisition }\end{array}$ & P_DI & נו & (0) & 51 & 35 & 0.02 & res \\
\hline & Masking \& Hovering & P_B2 & 10 & 10 & 10 & 10 & N/A & N/A \\
\hline \multirow{3}{*}{$\begin{array}{l}\text { Attack with } \\
\text { guided } \\
\text { missile }\end{array}$} & $\begin{array}{c}\text { NOE Flight \& Capture } \\
\text { attack point }\end{array}$ & P_C1 & 102 & 105 & 97 & 95 & 0.94 & No \\
\hline & $\begin{array}{l}\text { Radio communication } \\
\text { with command post }\end{array}$ & P_C2 & 37 & 43 & 50 & 41 & 0.12 & No \\
\hline & Pop-Up/Hovering & & & & & & & \\
\hline \multirow[b]{2}{*}{ Evasion flight } & Threat recognition/Evasion flight & & & & & & & \\
\hline & $\begin{array}{l}\text { Radio communication } \\
\text { with command post }\end{array}$ & P_D1 & 10 & 10 & 10 & 10 & N/A & N/A \\
\hline \multirow{4}{*}{$\begin{array}{l}\text { Attack with } \\
\text { guided rocket }\end{array}$} & $\begin{array}{l}\text { NOE Flight \& Capture } \\
\text { 1st attack point }\end{array}$ & & & & & & & \\
\hline & $\begin{array}{l}\text { Radio communication } \\
\text { with command post }\end{array}$ & P_EI & 121 & 138 & 139 & 118 & 0.03 & Yes \\
\hline & Pop-Up/Hovering & P_E2 & 39 & 46 & 42 & 42 & 0.80 & No \\
\hline & Masking & P_E3 & 10 & 10 & 10 & 10 & N/A & N/A \\
\hline \multirow{3}{*}{$\begin{array}{l}\text { Attack with } \\
\text { non-guided } \\
\text { rocket }\end{array}$} & $\begin{array}{l}\text { NOE Flight \& Capture } \\
\text { 3rd attack point }\end{array}$ & P_F1 & 75 & 97 & 114 & 61 & 0.00 & Yes \\
\hline & $\begin{array}{l}\text { Radio communication } \\
\text { with command post } \\
\text { Pop-Up/Target acquisition } \\
\text { \& Stand-by/Fire }\end{array}$ & P_F2 & 27 & 40 & 35 & 38 & 0.01 & Yes \\
\hline & Masking & P_F3 & 10 & 10 & 10 & 10 & N/A & N/A \\
\hline \multirow{3}{*}{$\begin{array}{l}\text { Attack with } \\
\text { auto-cannon }\end{array}$} & $\begin{array}{l}\text { NOE Flight \& Capture } \\
\text { 4th attack point }\end{array}$ & P_G1 & 111 & 127 & 135 & 105 & 0 & Yes \\
\hline & $\begin{array}{l}\text { Radio communication with } \\
\text { command post/Pop-Up/Hovering }\end{array}$ & P_G2 & 33 & 34 & 40 & 33 & 0.21 & No \\
\hline & Masking & P_G3 & 10 & 10 & 10 & 10 & N/A & N/A \\
\hline \multirow[t]{3}{*}{$\begin{array}{l}\text { Return } \\
\text { to base }\end{array}$} & $\begin{array}{c}\text { Radio communication } \\
\text { with command post } \\
\text { NOE flight }\end{array}$ & P_H1 & 39 & 47 & 49 & 36 & 0.01 & Yes \\
\hline & Contour flight & P_H2 & 137 & 156 & 174 & 145 & 0.00 & Yes \\
\hline & Total & P_T & 1003 & 1168 & 1217 & 987 & 0.00 & Yes \\
\hline
\end{tabular}

and C2 segments, while other NOE times are all significant. It can be reasoned that operating the guided missiles puts very little pressure on pilot performance. This is the same for the E2 segment for guided rockets, and the G2 segment for gun operation with TS. The total mission completion time for the pilot increases from (1) solo flight, (2) daytime, (3) bad weather, to (4) nighttime flying. It appears that the nighttime flying restricts the 


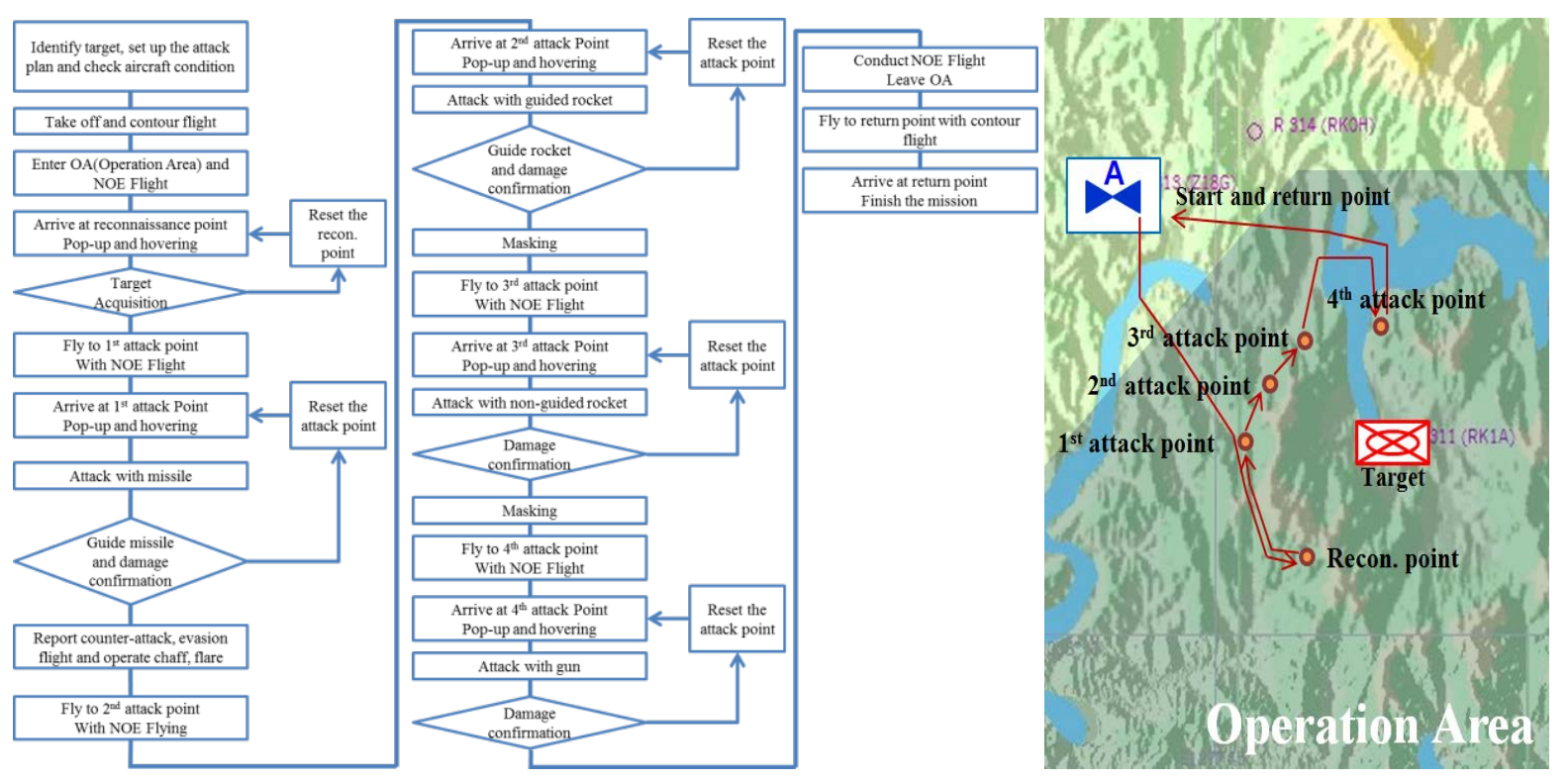

Figure 2. Mission procedure and operational map.

Table 4. Statistical analysis of the time data for the gunner.

\begin{tabular}{|c|c|c|c|c|c|c|c|}
\hline Task & Gunner & $\begin{array}{l}\text { Mission } \\
\text { code }\end{array}$ & Daytime & $\begin{array}{c}\text { Bad } \\
\text { weather }\end{array}$ & Nighttime & P-value & Significance \\
\hline $\begin{array}{c}\text { Flight to } \\
\text { operation area }\end{array}$ & Scout \& guide route & G_A2 & 185 & 222 & 231 & 0.00 & Yes \\
\hline \multirow{2}{*}{$\begin{array}{l}\text { Capture } \\
\text { reconnaissance } \\
\text { point and } \\
\text { target } \\
\text { acquisition }\end{array}$} & $\begin{array}{l}\text { Radio communication with command post } \\
\text { Target acquisition with TS } \\
\text { Radio communication with command post }\end{array}$ & G_B1 & 17 & 33 & 29 & 0.15 & No \\
\hline & Set the order of target priority & & & & & & \\
\hline \multirow{5}{*}{$\begin{array}{l}\text { Attack with } \\
\text { guided missile }\end{array}$} & Scout \& guide route & G_C1 & 112 & 115 & 107 & 0.92 & No \\
\hline & Radio communication with command post & & & & & & \\
\hline & Stand-by and ready for firing & G_C2 & 27 & 29 & 38 & 0.11 & No \\
\hline & $\begin{array}{l}\text { Fire \& guide missile with TS } \\
\text { Radio communication with command post }\end{array}$ & G_C3 & 10 & 14 & 12 & 0.13 & No \\
\hline & Scout \& guide route & G_E1 & 121 & 138 & 139 & 0.10 & No \\
\hline \multirow[t]{2}{*}{$\begin{array}{l}\text { Attack with } \\
\text { guided rocket }\end{array}$} & $\begin{array}{l}\text { Target acquisition with TS } \\
\text { Stand-by and ready for firing }\end{array}$ & G_E2 & 27 & 36 & 32 & 0.45 & No \\
\hline & Fire $\&$ guide missile with TS & G_E3 & 10 & 10 & 10 & 0.40 & No \\
\hline $\begin{array}{l}\text { Attack with } \\
\text { non-guided } \\
\text { rocket }\end{array}$ & $\begin{array}{c}\text { Scout \& guide route } \\
\text { Radio communication with command post }\end{array}$ & G_F1 & 228 & 279 & 299 & 0.00 & Yes \\
\hline $\begin{array}{l}\text { Attack with } \\
\text { auto-cannon }\end{array}$ & $\begin{array}{c}\text { Scout \& guide route } \\
\text { Target acquisition with TS } \\
\text { Stand-by and ready for firing }\end{array}$ & G_G1 & 18 & 19 & 25 & 0.16 & No \\
\hline \multirow[t]{2}{*}{ Return to base } & Scout \& guide route & G_H1 & 186 & 213 & 233 & 0.00 & Yes \\
\hline & Total & G_T & 1003 & 1168 & 1215 & 0.00 & Yes \\
\hline
\end{tabular}


pilot field of view, hence makes it more difficult to carry out the tasks at night. Since the pilot is very familiar with the simulator, the solo mission even becomes the shortest in terms of time. This suggests that the pilot is solely focused on the mission, while the crew coordination and communication becomes non-existent. Such situation may shorten the overall mission completion time, yet the actual workload becomes the highest. Solo mission likely causes the excessive fatigue to pilot, which in turn reduces the survivability and the mission success rate. It becomes obvious that a solo flight should not be recommended for attack helicopter pilots.

In Table 3 and Table 4, the pilot and gunner do not always coincide in terms of the significant difference among experiments. The gunner shows no difference in terms of task completion time, except when operating non-guided rockets and flight to and from the mission areas. Due to a high magnification camera of TS coupled with a limited number of enemy assets, the target identification and aiming seem quite easy for the gunner. However, the reconnaissance and the attack with non-guided rockets put a burden to the gunner, which demand a constant focus from the gunner in order to hit the target. The total mission time increases from (1) daytime, (2) bad weather, to (3) nighttime, which turn out to be statistically significant. On the contrary, the workload of gunner is the highest for bad weather. The gunner seems to focus intensely on his tasks under the rain and fog. When the solo flight is not considered, the mission completion time increases from (1) daytime, (2) bad weather, to (3) nighttime, for both pilots. This result attests that the weather conditions definitely affect the pilot and gunner performance.

\section{Pilot TLX Data Analysis}

To examined the changes in the workload according to the external environmental factors, the ANOVA test was conducted with a confidence level of $95 \%$. The workload was measured using the NASA-TLX, right after each mission is completed. Except the Physical Demand category of the gunner, all other areas show that the pilot and gunner workload is significantly affected by the external environmental factors. According to the TLX data, the pilot workload increases from (1) daytime, (2) bad weather, (3) nighttime, to (4) solo flight. For gunner, the order of increasing workload is (1) daytime, (2) nighttime, and (3) bad weather flight. For the solo flight, even though the weather condition is the best, the pilot workload appears to be the highest. This is quite reasonable, because the pilot must conduct every required task during the entire duration of the flight. It can be conjectured that the attack mission should be carried out with two pilots, in order to be more effective and survivable. For mental demand, the gunner load is at the highest in bad weather, while the pilot shows the high workload in nighttime flight. It is because that, for the gunner, the target finding, identification, and aiming can be more difficult under the rain and fog, rather than under a clear night sky. In nighttime flight, both pilot and gunner have a narrow field of view through the night vision screen (see Table 5).

\section{Conclusion}

Through the experiments, both pilots turn out to be significantly affected by the environmental factors. Due to the fact that the TS is one of the most essential equipment for night flying, target acquisition, and weapons aiming, there is a need to put the TS in an attack helicopter and do more research about the enhancement of its functionality. This includes the integration of enemy target database with the images acquired through the TS. Situated over several kilometers away, the identification of enemy assets can be quite difficult, just by looking at the images projected by the TS. The moving map display also helped the pilots to improve their situational awareness, by integrating critical mission and flight information. The moving map display should be a part of the battlefield network system in order to exchange combat information in real-time. This will substantially

Table 5. Comparison between the pilot and gunner data.

\begin{tabular}{ccc}
\hline \multicolumn{2}{c}{ Category } & Increasing Order \\
\hline Mission Completion Time & Pilot & (1) Solo $<<$ (2) Day $<<$ (3) Bad Weather $<<$ (4) Night \\
Workload & Gunner & (1) Day $<<$ (2) Bad Weather $<<$ (3) Night \\
& Pilot TLX & (1) Day $<<$ (2) Bad Weather $<<$ (3) Night $<<$ (4) Solo \\
\end{tabular}


increase the mission capability of attack helicopters. Considering the fact that the NOE flight is mandatory for attack helicopters, it is better to install the auto-pilot and automated flight systems to relieve the pilot from difficult terrain following tasks. The automatic hovering function can be especially beneficial, when the weather is windy and the pilot must maintain a steady attitude of his helicopter. The pilot can simply switch on the auto hovering and focus on the mission profile, instead of holding on to the control sticks. It is also recommended to install a weather penetrating radar (SAR) to overcome the limitations of optical targeting system. If the SAR is prohibited for every helicopter, a scout helicopter can be equipped with the radar and transmit the image data to the ensuing attack helicopters.

\section{Acknowledgements}

This work was supported by the Agency for Defense Development (ADD) under the Contract No. UD140066CD. The authors wish to express sincere gratitude for the financial support.

\section{References}

[1] Ball, R. (2003) The Fundamentals of Aircraft Combat Survivability Analysis and Design. 2nd Edition, American Institute of Aeronautics and Astronautics, Inc., Reston. http://dx.doi.org/10.2514/4.862519

[2] Ballentine, D. (2008) Gun Bird: A Marine Huey Pilot’s War in Vietnam. Naval Institute Press, Annapolis.

[3] Barnaby, F. (2003) The Role and Control of Weapons in the 1990s. A Division of Routledge, Chapman and Hall, Inc., New York.

[4] Bishop, C. (2005) Apache AH-64. Osprey Publishing Co., Long Island City.

[5] Bishop, C. (2006) Huey Cobra Gunship. Osprey Publishing Co., Long Island City.

[6] Bishop, C. (2008) Sikorsky UH-60 Black Hawk. Osprey Publishing Co., New York.

[7] Boyne, W. (2011) How the Helicopters Changed Modern Warfare. Pelican Publishing Co., Gretna.

[8] Charlton, S. and O’Brien, T. (2002) Testing and Evaluation: Handbook of Human Factors. 2nd Edition, Lawrence Erlbaum Associates, Inc., Mahwah.

[9] Gawron, V. (2008) Human Performance Workload and Situational Awareness Measures Handbook. 2nd Edition, CRC Press, an Imprint of Taylor \& Francis Group, Boca Raton. http://dx.doi.org/10.1201/9781420064506

[10] Grubb, G., Simon, R., Leedom, D. and Zeller, J. (1995) Effect of Crew Composition on AH-64 Attack Helicopter Mission Performance and Flight Safety. US Army Research Institute for the Behavioral and Social Sciences, Dynamic Research Corporation, Wilmington. 